\title{
THE APPLICATION OF FUZZY-AHP TO SCIENTIFIC MANAGEMENT OF ORDNANCE
}

Yao Shu-sheng, zhao Yu-zhuo and Gu De-qiao Ordnance Engineering Institute Shijiazhuang, China

\section{ABSTRACT}

On the basis of the study of paper ${ }^{(1)}$, this paper synthetically appraises the achievement in soft scientific research of management of ordnance with method of groups of Fuzzy-AHP and gives a simple and rational appraisal standard. having a great value in practice, this paper is appreciated by the upper department of management.

The system of management of ordnance is complicated and unclosed, there are many uncertain factors in the process of the management of ordnance. To put forward an appraisal standard with greater adoptation and with both concentrated intension and vast extension to the achievement in the soft scientific research of the management of ordnance the following three criteria must be abided by:

(1) subordination of the part to the whole.

(2) combination of the present effects with the long-range benefics

(3) combination of qualitative analysis with quantitative analysis on account of the specialities of the soft scientific research of the management of ordnance, a system which indicates the value, quality and investment indices of achievement in soft scientific research is set up and a multiobjective mathematical model of decision is contructed, with method of Analytic Hierarchy Process and by means of fuzzy appraisal, this paper gives a fuzzy appraisal matrix to synthetically give a synthetic score and a priority.

I. Introduction

A soft scientific research is interdepartmental synthetic research subject relating to various fields of natural and social. The organization of soft scientific research set up in the end of the 70 's is rapidly developed in the middle of the 80 's in China. In July of 1986, the symposium about national soft scientific research work was held by the State Science and Technology Committee of china in Beijing. It marks that the soft scientific research has extensively penetrated into fields of decisions of every grade and soft. At the same time, to suit the new situation that the thought to build our army has been strategically transferred, the soft scientific research is being vigorously developed in the management of ordnance and|has obtained greater achievements. With the subjects studied by soft science being so extensive, methods being synthetical and achievement being political, management method and appraisal standard must be different from traditional hard scientific research. So appraisal standards to the achievement in soft scientific research of ordnance should be worked out to promote the development of soft scientific research of ordnance and ralse efficiency of soft scientific research of management of ordnance

II. Directing Criteria to Evaluate the Achievement in Soft Sc1entific Research of Ordnance 
According to the development or variety of both subjective and objective conditions and by means of the elementary principle in which technology. economics, society and military interact and accordantly develop, soft scientific research of ordnance chiefly present new viewpionts, thoughts and methods on the aspects of commanding and managemept, order and acceptance, conservation and suppliment, maíntainance and guarantee, education adn training and so on, i.e.., to put forward some indices about scientific decision and modernizational management, such as strategy, plan, prediction and appraisal indices.

Basic characteristics of soft scientific research of ordnance are:

1. The Extension and Complexity of Researched objects.

Many objects studied by soft science are not singly natural, social or mitlitary phenomena but a complicated system consisting of technological, military social and natural. In term of work in ordnance management, for intance, it does not concern with specific technology reformation or maintainance of arms or equipments but study macrocopic management and decision of ordnance system in the whole.

\section{The Synthesis and Practice of Research Methods}

The target of soft scientific research is to serve decision of every and sort, i.e., to make achievements in soft scientific research into fields of decision so as to part them into parctical process of management or decision in different form, achievement in soft scientific research has strong politic and practical characterists.

just because of the elementary characterist is stated above that soft scientific research of management of ordnance holds, the appraisal standards to achievement in soft scientific research of management of ordnance can be determined as follows:

(1) The Principle of the part in Accordant to the Whole

The systme of soft sientific research of management of ordnance is a subsystem of developing strategic study of state and national defence, so the decision analysis of the subsystem must subordinate to the decision analysis of the whole.

(2) The Principle of Current. Effects Combining with Long-range Benefits

Along with realizing the long-range modernizational aim of ordnance garantee, soft scientific research of management of ordnance must raise present ability of ordnance guarantee and elevate the present level of management: of ordnance.

(3) The Principle of Qualitative Analysis Combining with Quantitative Analysis

Achievements in soft scientific analysis research are concerned with politics, economics, environment, psychology and so on. To make scientific calculation and comparison of appraisal, qualitative analysis must be combined with quantitative analysis. 
III. Appraisal Model of Soft Scientific Research of Management of Ordnance

According to the appraisal standard to achievements in soft scientific researchh of ordnance, a scientific, synthetic and objective system model of decision is -also constructed. Adopting Euzzy-AHP to make vertical and horizontal comparison, this paper gives the matrix A deciding the weighting of index, the fuzzy judgement matrix $R$ and a synthetic mark and priority.

(a). Hierarchy Structure of Appraisal System

A.rational index system can show how much the target has been achieved, and the system made in this paper takes the value and quality of the achievement and the research having been done in the achievement as appraisal stándards.

1. Value standard

(1) Benefit indices: including millitary, social, and enconomic benefits.

(2) Function indices: including effects on scientific decision and on modernizational management.

(3) Urgency and importance indices of the subject.

2. Quality Standard

Indices indicating level and progress of the subject: including the invention, the difficulty, the scale and the completion of the subject.

3. Investment Standard

Indices indicating scientific research efficiency: including such synthetic indices as related people, expenses and circle of research and manufacture. The strructure of appraisal system is showed as figure 1.

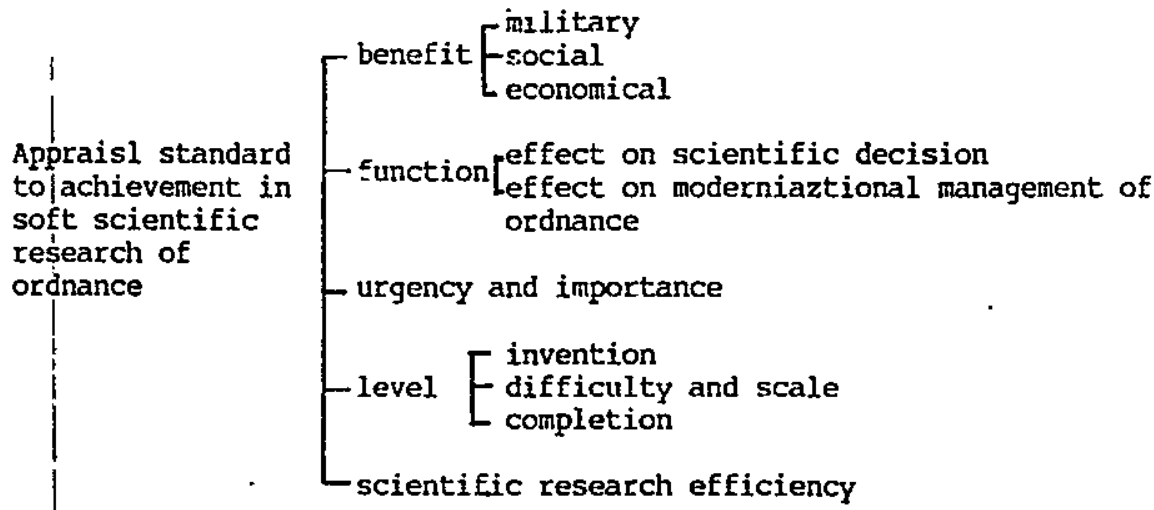

Figure 1. The hierarchy structure of appraisal .system

(b). Determining the weighting of the indices

According to the theory of Analytic Hierarchy Process presented by Professor T. L. Saaty, to quantitate groups of multicriterion synthetic apprassal, intuitive judgements by experts must be efficiently combined with quantitative conclusion by analysts, moreover, qualitative factors must be quan- 
titated and influence from subjective factors should be reduced to a certain degree, so the weighting of an undex can be scientifically determined.

It can be done as follows:

(i) Choosing a suitable ratio scale to construct judgment matrix.

(ii) Determining the relative weighting the index concerned according to each standard.

(iii) Determining the synthetic weighting of the index of each hierarchy obtain

where

$$
A=\left\{A_{1}, A_{2}, \ldots, A_{n}\right\}
$$

$A_{1}$ is the weighting of the index $i$.

\section{(iiii) Fuzzy Appraisal by Horizontal Grade}

According to the elementary theore of fuzzy mathematics, each index is evaluated to be grade $A, B, C$ or $D$. In fact, the appraisal of an index by grade is a process of dividing a continuous psychical amount into a number of grades. An index appraised to be gread B accords with grade A, $C$ or $D$ more or less. This is called subordination. The subordination of appraisal by horizontal grade can be obtained through simplified calculation. The process is as follows:

Fix the marks of grade A, B, C or D as 8, 6, 4 and 2, respectively, for convenience of calculation, two fictitious grades 10 and 0 are supplemented as in table 1

Table 1

\begin{tabular}{|c|c|c|c|c|c|c|}
\hline Grade & & A & B & $c$ & D & \\
\hline Score & 10 & 8 & 6 & 4 & 2 & 0 \\
\hline
\end{tabular}

Suppose that an appraisal index conforming to the two neighbouring grades to different degree does not accord with the other grades. If an appraisal index to an achievement comparatively accords with grade $C$ towards $B$, making it $C$, the subcalass of its subrodination can be wrtiten as

$\{\mathrm{F}\}=\{0, \mathrm{u}, 1,1-\mathrm{u}\} .(i<\mathrm{u}<1)$. If the index accords with $C$ towards $D$, making it $C$, the subcalass of its subordination can be written as

$\{F\}=\{0,1-u, 1, u\}$.

If the index accords with $C$ the same towards $B$ as towards $D$, making it

C, the subclass of its subordination can be written as

$\{\mathrm{F}\}=\left\{0,1,1, \frac{1}{2}\right\}$.

From experience, we know the gap between of $C^{-}$and $D^{+}$must be greater than that between $C^{+}$and $C^{*}$ setting $(C-D) /(C-C)=3 / 2$, then $u=11 / 14$, so the fuzzy martix is 


$[F]=\left(\begin{array}{cccccc}11 / 14 & 1 & 3 / 14 & 0 & 0 & 0 \\ 1 / 2 & 1 & 1 / 2 & 0 & 0 & 0 \\ 3 / 14 & 1 & 11 / 14 & 0 & 0 & 0 \\ 0 & 11 / 14 & 1 & 3 / 14 & 0 & 0 \\ 0 & 1 / 2 & 1 & 1 / 2 & 0 & 0 \\ 0 & 3 / 14 & 1 & 11 / 14 & 0 & 0 \\ 0 & 0 & 11 / 14 & 1 & 3 / 14 & 0 \\ 0 & 0 & 1 / 2 & 1 & 1 / 2 & 0 \\ 0 & 0 & 3 / 14 & 1 & 11 / 14 & 0 \\ 0 & 0 & 0 & 11 / 14 & 1 & 3 / 14 \\ 0 & 0 & 0 & 1 / 2 & 1 & 1 / 2 \\ 0 & 0 & 0 & 3 / 14 & 1 & 11 / 14\end{array}\right)$

IV. Synthetic Appraisal

on condition that the weighting of each index and appraisal by horizontal grade is determined, appraisal can be started. The steps are as follows:

1.) Designing a table of achievements in soft scientific research

In the table there are all ten indices, each of which is appraised to be grade $A, B, C$ or $D$.

2. Appraisal by Experts

At first, each index in the table is to be objectively, fairly and singly juidged by the appraisors, then only one suitable grade to appraise the index cán be determined.

3. Making a fuzzy membership matrix

on basis of statistics of appraisal by experts, the fuzzy appraisal matrix cạn be constructed as

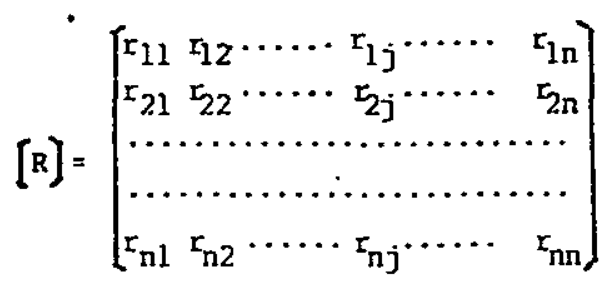

where

$r_{i j}$ is times of appraisal of the index $i$ in grade $j$.

4 Making a synthetic appraisal and giving a score

$$
\begin{array}{ll} 
& S=(A)^{T}[R] \quad[F] \quad(Q) \\
& (Q)=(10,8,6,4,2,0)^{T}
\end{array}
$$

5! Feed back the sum of the score of each index to experts, organize the experts to discuss it, then let the experts to write their reports on appraisal in person, make calculations according to the reports and give the final result

v. The Application Example 
The three pleces of achievement in soft scientific research of ordnance system for example, are appraised with method of synthet zc Fuzzy appraisal Suppose the vector of the weighting as

$$
(A)=(0.12,0.05,0.08,0.14,014,0.12010,010,0.10,0.01)
$$

The the synthetic appraisal matrıx to the first plece of achievement is:

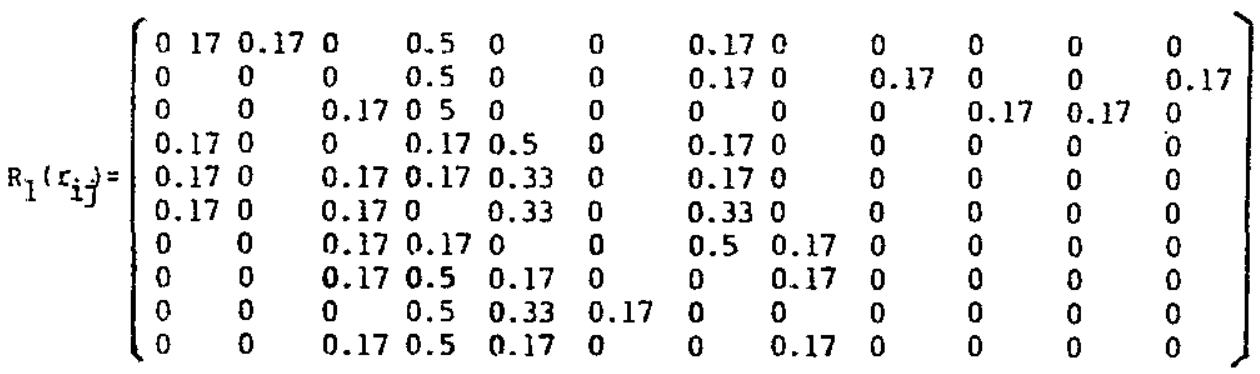

where

$$
\begin{aligned}
& r_{i j}=p_{i j} / n \\
& p_{i j} 1 s \text { the number of the experts in support of the index } i \text { being } \\
& \text { appraised the grade } j, n \text { is the sum of the experts. }
\end{aligned}
$$

The synthetic appraisal matrixes $R_{2}$ and $R_{3}$ to the second and third peice of achievement, respectively, can be given in the similar method stated above. The final result of the appraisal is sa following table:

Tabel 2.

\begin{tabular}{|l|ccc|}
\hline achievement & 1 & 2 & 3 \\
\hline score & 79.6 & 69.5 & 59.8 \\
\hline
\end{tabular}

The result approximately accords with the result of the intuitive judg. ment by experts that, the first and second pieces of achievements are appraised as second prize and the third piece of achievement is appraised as third prize.

\section{Conclusion}

1. It's a successful expereiment to apply the Fuzzy-AHP is in the management of ordnance. The results obtained approximately accord with macroscopic judgment by groups of experts. So this paper makes a great progress in the combination of qualitative analysis with quantitative analysis and is appreciated by the upper department of management, as for Fuzzy-AHP, its application has a greater extension and has broad prospects in either prediction of talent, demanstration of plan or management of ordnance.

2. In the process of the practical application, how to organically combine analytic hierarchy process with Fuzzy judgment martrix depends upon feeding back th judgment matrix (R) to groups of experts in time so as to provide experts with an opportunity to regulate their intention to make a more 

objective and practical synthetıc judgment.

3. The application of software is still to be developed and broadened so as to find its stronger adoptation in larger range.

\section{REFERENCES}

Saaty, T.L., 1980. The Analytical Hierarchy Process, McGraw-Hill Inc.

Liu Bao, 1987, Introduction to Systems Engineering, Machinary Industry Press, Beijing, ( in Chinese)

Xu Shubo, 1988, Principle of the AHP, Tianjin University Press, $($ in Chinese)

He zhongxong, 1985, Fuzzy Mathematics and Its Applications, Tianjin Science and Technology Press, (in Chinese) 